AperTO - Archivio Istituzionale Open Access dell'Università di Torino

\title{
Reliability-based design for debris flow barriers
}

\section{This is the author's manuscript}

Original Citation:

Availability:

This version is available http://hdl.handle.net/2318/1711045

since 2019-09-18T09:31:32Z

Published version:

DOI:10.1007/s10346-019-01268-7

Terms of use:

Open Access

Anyone can freely access the full text of works made available as "Open Access". Works made available under a Creative Commons license can be used according to the terms and conditions of said license. Use of all other works requires consent of the right holder (author or publisher) if not exempted from copyright protection by the applicable law. 


\section{Reliability-based design for debris flow barriers}

3 Vagnon, Federico

4 Department of Earth Science, University of Turin, Via Valperga Caluso 35, 10125, Turin, Italy

5 Corresponding author: federico.vagnon@unito.it, Tel: +39 0116705325

6

7 Ferrero, Anna Maria

8 Department of Earth Science, University of Turin, Via Valperga Caluso 35, 10125, Turin, Italy

9 anna.ferrero@unito.it

10

11 Alejano, Leandro R.

12 Department of Natural Resources and Environmental Engineering, University of Vigo, Galicia, 13 Spain

14 alejano@uvigo.es 
In the European Union since 2010, the design of any type of structures must comply with EN-1997 Geotechnical Design (CEN 2004) (EC7) referring to engineering projects in the rock mechanics field. However, the design of debris flow countermeasures in compliance with EC7 requirements is not feasible: EC7 uses partial safety factors for design calculations, but safety factors are not provided for phenomena such as debris flows and rock falls. Consequently, how EC7 can be applied to the design of debris flow barriers is not clear, although the basic philosophy of reliability-based design (RBD), as defined in EN1990 (CEN 2002) and applicable to geotechnical applications, may be a suitable approach.

However, there is insufficient understanding of interactions between debris flows and structures to support RBD application to debris flow barrier design, as full-scale experimental data are very limited and difficult to obtain. Laboratory data are available but they are governed by scale effects that limit their usefulness for full-scale problems.

The article describes an analysis, using the first-order reliability method (FORM), of two different datasets, one obtained through laboratory experiments and the other reflecting historical debris flow events in the Jiangjia Ravine (China). Statistical analysis of laboratory data enabled a definition of the statistical distributions of the parameters that primarily influence debris flow and barrier interactions. These statistical distributions were then compared to the field data to explore the links between flume experiments and full-scale problems.

This paper reports a first attempt to apply RBD to debris flow countermeasures, showing how the choice of the target probability of failure influences the barrier design resistance value. An analysis of the factors governing debris flows highlights the applicability and limitations of EN1990 and EN1997 in the design of these rock engineering structures. 


\section{$39 \quad$ Keywords}

40 Eurocode 7 (EC7); Reliability index; First-order reliability method (FORM); Partial safety factor;

41 Debris flow; Mitigation design. 


\section{Introduction}

43 Debris flows are extremely rapid gravitational movements that occur widely on Earth. They are among the most devastating landslide processes owing to their unpredictability, their total absence of premonitory signals, their high velocities and their long travel distances. Many mitigation strategies have been developed in recent years to reduce the associated risk, and both active and passive measures are used to reduce the magnitude and frequency of debris flows and to change the vulnerability of debris flow basins. Although passive measures (hazard mapping and correct landuse planning) are more advisable than active measures (protection structures), the latter are often essential in order to reduce risk (Jakob and Hungr 2005).

Common active measures can be classified as rigid measures - such as close-type check dams, open-type sabo dams and concrete-slit sabo dams - and flexible measures, mainly net barriers designed as a function of the deformation capability. Although very different in terms of components, drainage capacity and construction methodology, their main requirement is to counteract the impact forces underlying debris flow, dissipate its kinetic energy and totally or partially retain the flowing material.

The design of countermeasures is still an open issue. While there are many approaches to evaluating impact pressure (Hungr et al. 1984; Armanini and Scotton 1992; Hubl et al. 2009; Vagnon and Segalini 2016), uncertainty regarding flow characteristics (velocity and thickness) tends to be high and difficult to quantify (Jakob and Hungr 2005; Vagnon et al. 2015).

With this issue in mind, the Geotechnical Engineering Office of the Government of Hong Kong introduced the first technical basis for the design of standardized debris-resisting barrier modules to mitigate natural terrain landslide hazards (Sun et al. 2003). While its report analyses different debris flow run-out models and barrier types, there is no mention of the probability of failure of these structures. In 2009, the

Austrian Standard Institute proposed the Österreichischen 
Normungsinstituts Regeln (ONR) 24800 series to design torrent control structures. ONR 24802 (2011) defines loading scenarios for debris flow protection structures, specifically providing information on limit state design and failure mode for check dams, as well as partial safety factors for structural (STR) and geotechnical (GEO) limit state actions.

When considering the design of debris flow barriers, uncertainties regarding all debris flow phases are difficult to quantify; consequently, since the degree of reliability is not evaluated, the probability of failure remains unknown.

The interaction between debris flow and barrier is only dealt with in passing in EN-1997 Geotechnical Design (CEN 2004) (EC7), and although protection structures are widely used for mitigation purposes, there are no specific indications regarding their design. In previous works (Vagnon et al. 2016; Vagnon et al. 2017), the authors highlighted limitations in the applicability of EC7, and in particular the limit state design (LSD) approach to designing this type of structure due to the limited availability of experimental data. The set of proposed partial factors are clearly inadequate since they refer only to flow density and internal friction angle and neglect other relevant debris flow parameters such as flow velocity and thickness.

Uncertainties are considered in EC7: the concept of characteristic value introduced by the LSD approach allows a cautiously mean value to be selected, averaged over the failure surface and taking into account variability and uncertainties in the very definition of the parameter. However, spatial correlations between the same kind of parameters and cross-correlations between different parameters are still missing (Low and Phoon 2015). Many studies have demonstrated the presence of cross-correlations that are not entirely negligible, especially between soil parameters. Concerning debris flow, in a recent work, Vagnon and Segalini (2016) demonstrated a correlation between velocity and flow height.

For all the above reasons, the authors believe that a design approach based on a target reliability 
index (Duncan 2000; Baecher and Christian 2003) could be a useful complementary tool in defining a uniform probability of failure for geotechnical structures. Reliability-based design (RBD) can provide additional insights into EC7 design and can be applied where partial factors have yet to be proposed (by EC7) to cover the uncertainties associated with less common parameters (Low and Phoon 2015), as is the case of debris flow countermeasures. Moreover, as stated by Duncan (2000), reliability calculations are a means for evaluating the combined effects of uncertainties and for distinguishing between conditions where uncertainties are very high, a clear example of which is evaluation of debris flow impact pressure.

RBD is widely used, especially in civil engineering, and has been applied to the study of slope stability (Li et al. 2016; Zhao et al. 2016; McGuire and VandenBerge 2017; Huang et al. 2018). EN 1990 (2002), the European standard that describes the basis for structural design, requires structures to be designed with an appropriate degree of reliability, which varies as a function of three reliability classes (RCs) for the ultimate limit state. The problem, however, is that there is no clear indication of the best class to choose and EC7, moreover, does not suggest any relationship between the RCs and geotechnical classes (Section 2.1 EC7). Normally, a reliability index greater than 3.8 for a 50 -year reference period (corresponding to RC2) is recommended.

The purpose of this paper is to perform RBD for debris flow protection barriers and to propose a methodology for evaluating the probability of failure for such complex problems. Two databases, one obtained from laboratory experimental tests and one based on real events in the Jiangjia Ravine basin in China, are used as a basis for an analysis of the complementary relationship between EC7 and RBD.

This paper, which, as far as we are aware, represents a first attempt to apply RBD to debris flow protection barriers, shows how the choice of a target probability of failure influences the resistance value of the barrier design. The analysis covers factors governing debris flow as well as variations - 
114 as a function of the probability of failure - in partial safety factors computed using the Excel

115 spreadsheet platform for the first-order reliability method (FORM) developed by Low and Tang 116 (2007).

\section{FORM procedures}

119 Reliability analyses are commonly expressed by the Hasofer-Lind (1974) reliability index $\beta$, which 120 can be related to probability of failure, $P_{f} . P_{f}$ can be estimated as follows:

where $\Phi$ is the normal cumulative probability function.

Since the reliability index is calculated by minimizing the quadratic form tangent to the limit state surface at the most probable failure point (Figure 1), defining $\beta$ makes it possible to determine the coordinates of what is called the design point $\left(x^{*}\right)$. Physically denoted is the tangency of the expanding dispersion ellipsoid with the failure domain surface.

Figure 1. Illustration of the reliability index in a plane with two negatively correlated random 131 variables.

133 While numerous methods to perform reliability analyses have been described, e.g., by Ditlevsen 134 (1981), Ang and Tang (1984), Madsen et al. (1986), Low and Tang (1997), Haldar and Mahadevan 135 (1999), Melchers (1999) and Baecher and Christian (2003), the most consistent approach is FORM, 136 which is a useful spreadsheet-automated constrained optimization approach (Low and Tang, 2007). 
In the spreadsheet, the equation for evaluating $\beta$ is:

$$
\beta=\min _{\mathrm{x} \in \mathrm{f}} \sqrt{\vec{n}^{\mathrm{T}}[\mathrm{R}]^{-1} \overrightarrow{\mathrm{n}}}
$$

141 where $\vec{n}$ is a dimensionless vector defined as $\vec{n}=\left(x-\mu^{N}\right) / \sigma^{N}, x$ is a vector representing the set of

142 random variables, $\mu^{N}$ and $\sigma^{N}$ are the vectors of normal mean and normal standard deviation

143 evaluated using Rackwitz-Fiessler equations (1978), $R$ is the correlation matrix, and $f$ is the failure 144 domain.

145 For each value of $n_{i}$ trialled by the Excel Solver, a short and simple Excel VBA code automates the 146 computation of $x_{i}$ from $n_{i}$, for use in the constraint performance function $\mathrm{g}(\mathrm{x})=0$, via $\mathrm{x}_{\mathrm{i}}=\mathrm{F}^{-1} \Phi\left[\left(\mathrm{n}_{\mathrm{i}}\right)\right]$, 147 where $\Phi$ is the standard normal distribution and $F$ is the original non-normal distribution.

148 The use of Equation 2 is necessary because, as will be discussed in later sections, the leading 149 variables in debris flow phenomena follow non-normal distributions.

\section{RBD versus EC7 design}

152 EC7 is based on LSD, a semi-probabilistic method in which partial factors are applied to 153 characteristic parameter values in order to account for parameter uncertainty and so achieve designs 154 with a certain target reliability (Figure 2).

Figure 2. EC7 limit state design: probabilities of actions and material resistance.

158 The aim underlying LSD, which is based on reliability analyses, is to provide structures with a 159 uniform probability of failure (Figure 2). The fundamental principle is to verify that design 
160

161 of three different design approaches, described in detail in Section 2.4.7.3.4 of EC7 (EN 1997-

162 1:2004). Broadly speaking, EC7 requires the use of partial safety factors aimed at reducing 163 resistance and enhancing actions. While the efficacy of this approach has been demonstrated in civil 164 engineering, its efficacy in the geotechnical field has raised many doubts, particularly in rock 165 mechanics, where variability and uncertainty associated with materials (soil and rock) play a 166 fundamental role (Harrison 2014; Lamas et al. 2014; Vagnon et al. 2020). Furthermore, in EC7 a 167

181 obtain.

182 In sum, in the case of debris flow phenomena, RBD provides insights missing from EC7 design 183 when statistical information on key parameters is available, when partial factors have not been 
proposed and when input parameters are correlated.

185

\section{Statistical analysis of laboratory and real debris flow motion characteristics}

187

$$
\alpha=\frac{p_{\text {measured }}}{\rho v_{f}^{2}}
$$
dataset). (1984):

As stated above, the main limitation of the RBD approach is the availability of data to conduct robust statistical analyses and to define the probability distribution of the parameters considered in the performance function. Evaluated below is the fit between probabilistic models and debris flow motion data, using a dataset of experimental laboratory tests performed by the authors (laboratory dataset) and a dataset of 139 real events that occurred in the Jiangjia Ravine basin in China (field

The laboratory dataset contains flow velocity and thickness values as well as the dynamic coefficients for 82 experimental laboratory flume tests (Figure 3) in which a debris flow was created by the rapid emptying of a hopper into the flume. Different material volumes (0.065 to $\left.0.075 \mathrm{~m}^{3}\right)$ and different flume slopes $\left(30^{\circ}\right.$ to $\left.35^{\circ}\right)$ were used in the experiments. Velocity, flow height and the impact force were recorded using four ultrasonic levels located along the centre line of the channel and four load cells installed directly on the barrier.

The dynamic coefficient is a dimensionless parameter used in hydrodynamic models to evaluate impact pressure on obstacles/structures. Dependent on the grain size distribution of the flow and barrier/obstacle characteristics (Vagnon and Segalini 2016), for the purposes of this research it was indirectly derived from experimental and field data using Hungr et al.'s hydrodynamic model 
where $p_{\text {measured }}$ is the impact pressure measured in $\mathrm{Pa}, \rho$ is the flow density in $\mathrm{kg} / \mathrm{m}^{3}$, and $v_{f}$ is the 208 impacting flow velocity in $\mathrm{m} / \mathrm{s}$.

209 A more detailed description of laboratory apparatus and instruments can be found in Vagnon and 210 Segalini (2016).

212 Figure 3. Flume setup and location of measurement devices.

214 The field dataset includes thickness $\left(h_{f}\right)$, density $(\rho)$, channel width $(\mathrm{B})$, duration $(\mathrm{t})$ and velocity $\left(v_{f}\right)$ 215 values for 139 historical events that took place between 1961 and 2000 in the Jiangjia Ravine basin 216 located in the Dongchuan area of Yunnan Province in China (Zhang and Xiong 1997; Kang et al. 217 2006, 2007; Hong et al. 2015). This basin experiences numerous debris flow events each year (up to 218 28) that cause great damage to local infrastructure (Hong et al. 2015). Debris flows, which mainly 219 occur during the rainy season (June to September), lead to highly fractured rocks and colluvium 220 being eroded and rapidly carried to the valley floor (Zhou and NG 2010).

221 An unparalleled record is available of long-term observations of this site by the Dongchuan Debris 222 Flow Observation and Research Station (DDFORS), which set up a permanent monitoring station in 223 the downstream area in the 1960s. Flow velocity is measured by a stopwatch in two marked 224 sections along the gully, front head thickness is measured by a supersonic lever meter and surge 225 density is measured by direct sampling of debris flows. The dynamic coefficient was back226 calculated using Equation 3. Table 1 shows the main features of the datasets.

228 Table 1. Principal laboratory and field dataset features. 
230 The raw data from the two datasets was used to perform a statistical analysis for the parameters 231 listed in Table 2.

Table 2. Main statistical parameters for the laboratory and field datasets.

Each distribution was sorted into k-intervals in order to obtain the relative frequency of the real data. The following equation was used to evaluate the number of classes:

$k=2 n^{0.4}$

240 where $k$ is the number of classes and $n$ is the dimension of the population data. For the laboratory 241 and field datasets, the number of classes was, respectively, 12 and 14.

242 The basic idea behind this statistical analysis, in addition to defining probabilistic models for each 243 parameter, was to evaluate the interchangeability of models between laboratory and field datasets. 244 The probabilistic analysis was performed first for the laboratory measurements and then for the 245 field measurements.

246 The statistical distribution of laboratory measurements for $\mathrm{v}_{\mathrm{f}}, \mathrm{h}_{\mathrm{f}}$ and $\alpha$ were simulated using seven 247 probabilistic models: normal, lognormal, exponential, Gumbel, generalized extreme value (GEV), 248 Gamma and Weibull. Since there was no prior knowledge on debris flow phenomena, the suitability 249 of each model for predicting distributions of $\mathrm{v}_{\mathrm{f}}, \mathrm{h}_{\mathrm{f}}$ and $\alpha$ was not known. While the Gumbel and 250 GEV distribution have been used in hydraulic analyses to evaluate the return period for a specific 251 river flood height, there are no suggestions of their applicability to the debris flow field.

252 The goal was to verify which probability distributions best fitted the laboratory data and then try to 
apply those distributions to the field data. The fit of each probabilistic model was assessed using 254 two statistical goodness-of-fit (GoF) tests: Chi-square $\left(\chi^{2}\right)$ and Anderson-Darling (AD). The 255 probabilistic model not rejected by both GoF tests was then used as input for the Low and Tang 256 (2004) spreadsheet.

257 Table 3 lists the results of the GoF tests for the three considered variables, $\mathrm{v}_{\mathrm{f}}, \mathrm{h}_{\mathrm{f}}$ and $\alpha$. The results 258 of GoF tests highlighted that: (i) the GEV model is suitable for simulating all three parameters, and 259 (ii) the Gumbel model acceptably simulates the distributions of $v_{f}$ and $\alpha$.

260 The described procedure is a first attempt to statistically analyse debris flow events. The analogy 261 with other river processes, in which extreme value distributions are satisfactorily applied to describe 262 rare events such as extreme floods, is undeniable.

Table 3. Laboratory measurements: two statistical goodness-of-fit test results for $\mathrm{v}_{\mathrm{f}}, \mathrm{h}_{\mathrm{f}}$ and $\alpha$.

Figure 4 shows a comparison between cumulative probability distributions for $v_{f}, h_{f}$ and $\alpha$ and the corresponding predictive probabilistic model.

Figure 4. Laboratory data: comparison of cumulative probability distributions for measured and theoretically predicted $\mathrm{v}_{\mathrm{f}}(\mathrm{a}), \mathrm{h}_{\mathrm{f}}(\mathrm{b})$, and $\alpha(\mathrm{c})$.

272 From the laboratory data it was observed that velocity, thickness and dynamic coefficient values might be approximated using a GEV distribution. However, since debris flow experimental tests are 274 a scaled-down representation of the real phenomenon, presuming a GEV distribution (or any other 275 distribution) might be unjustified without a comparison with real data. The authors verified, 
276 following the same procedure as described above, whether this hypothesis could be confirmed using 277 the Jiangija Ravine dataset of real values.

278 Table 4 and Figure 5 summarize the results of the statistical analysis of the field data. Concerning $279 v_{f}$, the GEV distribution passed the Chi-square test but failed the AD test; however, Figure 5a 280 clearly shows that there exists an acceptable approximation between the GEV and the cumulative 281 distributions of the measured data, as the mean difference between the two curves is less than $10 \%$. 282 As for the dynamic coefficient $\alpha$, this could be approximated using both the lognormal and GEV 283 distributions. Concerning flow thickness, the Gumbel, GEV and Weibull distributions satisfied all 284 the criteria of the GoF tests. The hypothesis was therefore confirmed: the GEV properly describes 285 the probability distributions of thickness and velocity in flow-like phenomena.

Table 4. Field measurements: two statistical goodness-of-fit test results for $v_{f}$ and $h_{f}$.

Figure 5. Field data: comparison of the cumulative probability distributions for measured and theoretically predicted $\mathrm{v}_{\mathrm{f}}(\mathrm{a}), \mathrm{h}_{\mathrm{f}}(\mathrm{b})$ and $\alpha(\mathrm{c})$.

The key point concerning the statistical treatment of debris flow events is that, while the scientific literature includes some examples of extreme value distributions satisfactorily applied to debris flow magnitude (Helsen et al. 2002; Marchi and D’Agostino 2004), no examples exist for flow characteristics due to a lack of monitoring data. However, the statistical analysis confirms that both laboratory and field parameter distributions can be approximated using a GEV distribution.

\section{RBD of debris flow barriers}


As described above, FORM requires the introduction of a performance function $\mathrm{g}(\mathrm{x})=0$ that generally reflects the difference between resistances and the effects of actions.

301 In this research, the following equation was used:

$g(x)=R-\rho \alpha v_{f}^{2} h_{f} B$

where $\mathrm{R}$ is barrier resistance in $\mathrm{N}, \rho$ is flow density in $\mathrm{kg} / \mathrm{m}^{3}$ (equal to $1920 \mathrm{~kg} / \mathrm{m}^{3}$ and $2155 \mathrm{~kg} / \mathrm{m}^{3}$, respectively, for laboratory and field data), and $B$ is channel width in $\mathrm{m}$ (equal to $0.39 \mathrm{~m}$ and $36 \mathrm{~m}$, respectively, for laboratory and field data).

Equation 5 represents the difference between barrier resistance and flow thrust evaluated using 309 Hungr et al.'s hydrodynamic model (1984). Dynamic impact force was calculated using the 310 momentum equation, with the impacting mass considered to be a prism travelling with uniform 311 velocity equal to mean flow velocity. Since lateral velocity variation was negligible at the flow 312 front, the front thrust results were more significant. Flow density, assumed to be constant during the 313 impact phase, was represented by a mean value for the solid and fluid components.

314 Low and Tang (1997) highlighted that correlation between variables produces a rotation of the 315 dispersion hyperellipsoid, and consequently, a variation in the probability of failure. Table 2 shows 316 that velocity and height flow and velocity and dynamic coefficient are negatively correlated, as 317 discussed in Vagnon and Segalini (2016).

318 Since the barrier is manmade and built following engineering criteria, resistance probability was 319 assumed to be normally distributed, with standard deviation equal to $3 \%$ of the mean.

320 EN1990 Annex C Table C1 gives a list of reliability index values, $\beta$, as a function of probability of 321 failure, $\mathrm{P}_{\mathrm{f}}$. Using those values, a RBD approach to a debris flow rigid barrier is proposed, based on 
an analysis of both laboratory and field datasets. In particular, the design points for each variable were identified and their distance from the corresponding mean was evaluated.

Table 5. Relationship between $P_{f}$ and $\beta$.

Figure 6 depicts the Low and Tang (2007) FORM computational approach in the Microsoft Excel spreadsheet platform. The spreadsheet allows the value of the reliability index, $\beta$, to be minimized, starting from the main parameters that describe debris flow and their respective probabilistic distributions. Required for each distribution are the mean (Para1) and standard deviation (Para2). Microsoft Excel Solver automatically changes the $\mathrm{x}^{*}$ column in order to find the minimum value of $\beta$, by imposing two constraints: i) $\mathrm{g}(\mathrm{x})=0$ and ii) upper limits for the GEV distributions.

Figure 6. Determining the reliability index $\beta$ and the coordinates of the design point $x^{*}$ for a hypothetical rigid debris flow barrier.

In Figure 6, the column $x^{*}$ represents the coordinates of the design point, i.e., the point where the four-dimensional equivalent dispersion ellipsoid is tangential to the limit state surface. These coordinates are the most probable failure combination for the debris flow parameters.

Listed in Table 6 as a function of the probability of failure are the combinations of design parameters for the laboratory and field data. At first sight, design resistance, velocity and dynamic coefficient values increase as the reliability index increases. Design thickness for laboratory data seems not to be influenced by the probability of failure; rather, considering the field data, it behaves similarly to the other design parameters. This behaviour is explained by smaller thickness variations 
in the laboratory data compared to the field data.

Table 6. Design parameters evaluated for a reliability-based design approach as a function of reliability index values proposed in EN 1990 Annex C Table C1.

As discussed in relation to the statistical analysis, the reliability method is directly correlated with the partial safety factor concept introduced in EC7. In fact, the coordinates of the design point allow the partial safety factors to be evaluated, as, once the probabilistic distribution of the parameters is defined, the characteristic values can be back-calculated assuming the $i^{\text {th }}$-percentile of the probability distribution. The partial safety factor is the ratio between the characteristic value and the design parameter value.

Figure 7 shows flow barrier partial safety factor trends $\gamma$ for each parameter, for laboratory data (circles) and field data (squares), as a function of the probability of failure, $\mathrm{P}_{\mathrm{f}}$. Partial safety factors were calculated considering the $50^{\text {th }}, 70^{\text {th }}$ and $90^{\text {th }}$ percentiles, indicated in black, dark grey and light grey, respectively.

Main findings can be summarized as follow:

361 - Generally, the higher the percentile value, the lower the partial safety factor value. The 362 opposite occurs with partial safety factors for resistance, as these are reducing factors.

363 - Partial safety factors for resistance are independent from probability of failure values and are 364 the same for both laboratory and field datasets (Figure 7a). This reflects a low degree of 365 uncertainty in relation to barrier resistance evaluation.

366 - Even though the velocity and dynamic coefficient partial safety factors are different (Figures $7 \mathrm{~b}$ 367 and $7 d$ ), their trend is the same. In fact, those two figures suggest that characteristic values for $v_{f}$ and $\alpha$ should be increased and that $\alpha$ should be increased more than $v_{f}$. 
- Significant differences are evident for partial safety factors for thickness, as for laboratory data, they remain constant and close to unity, whereas for field data, the trend is the same as for velocity and dynamic coefficient. The most plausible explanation is the greater variability in thickness measured in the field compared to in small-scale laboratory tests.

Figure 7. Partial safety factor dependence on resistance (a), velocity (b), thickness (c) and dynamic coefficient (d) as a function of probability of failure for laboratory data (circles) and field data (squares). Three percentiles were considered for each parameter probability distribution: $50^{\text {th }}$ (black), $70^{\text {th }}$ (dark grey) and $90^{\text {th }}$ (light grey).

\section{Summary and conclusions}

380 Since the impact of debris flow against rigid and flexible protection structures is still not clearly understood, the design of countermeasures is problematic. First, design-related uncertainties complicate evaluation of the probability of failure, and second, further uncertainties arise in the assumptions that engineers are forced to make due to the lack of data. No clear guidelines as yet exist for the safe design of debris flow protection barriers. As pointed out elsewhere (Vagnon et al. 2016, Vagnon et al. 2017), the EC7 LSD approach based on partial safety factors is not fully applicable, since the proposed partial safety factor set does not cover the main parameters associated with debris flow phenomena. We argue that structure interaction problems can be better analysed using a RBD approach that investigates the probability of failure associated with parameter variability.

The RBD approach to designing debris flow barriers described above complements the EC7 LSD 391 approach and highlights the associated limitations and advantages. The main limitations are data availability and the possibilities for analysing data in a statistical framework. As mentioned, the 
lack of monitoring data for real debris flow events forces assumptions to be made regarding 394 statistical distribution.

395 In a more rigorous approach to this problem, the authors of this paper, drawing on laboratory and 396 field data, selected the probability distributions that best fit the experimental data and verified the 397 resulting probability distributions against the real dataset.

398 GEV has been demonstrated to be capable of simulating probabilistic distributions for flow height, 399 velocity and thickness. The GEV distribution is frequently used to model flood event frequencies. 400 Debris flows, we suggest, can be considered as a particular kind of riverine process and, on the 401 basis of this analogy and the results of this research underpinned by rigorous statistical calculations, 402 it should be possible to assume probabilistic extreme distributions for debris flows. However, to 403 confirm or refute this assumption, further studies would need to be done using other datasets.

404 Regarding probability distributions, an interesting finding was that both laboratory data and field 405 data follow the same statistical model, namely the GEV distribution, for all the variables. This 406 further confirms the hypothesis that small-scale laboratory tests can simulate and obtain data for 407 full-scale flow barrier design.

408 Another limitation of the RBD approach arises in the selected performance function: changing the 409 impact model causes the value of $\beta$ to change and this, in turn, causes the probability of failure to 410 change. Sensitivity analyses would therefore be required in order to quantify the effect of the 411 selected performance function.

412 The RBD approach allows back-calculated partial safety factors to be applied in the LSD method 413 proposed by EC7. These partial safety factors have the advantage that they are associated with a 414 known target failure probability. However, a question remains as to the universal meaning of partial 415 safety factors for this type of geoengineering problems: the application of a set of partial safety 416 factors does not allow determination of the associated probability of failure in the Limit State 
417 Design (LSD) approach, contrary to the RBD approach. Moreover, there are not enough elements 418 and accumulated experience, as in other geotechnical contexts (for instance, regarding the 419 interactions between soils and foundations), to extend the partial safety factor approach to 420 interactions between debris flows and barriers with some certainty of safety.

421 In conclusion, the RBD method provides insights into EC7 design for debris flow countermeasures 422 and is a useful design approach for protection structures based on determining an associated 423 probability of failure.

Acknowledgement: We gratefully acknowledge Ailish M. J. Maher for the language polishing of 426 the final version of the manuscript.

\section{References}

430 Ang HS, Tang WH (1984) Probability concepts in engineering planning and design. Decision, Risk 431 and Reliability. Vol. 2 New York: J. Wiley

Armanini A, Scotton P (1992) Experimental analysis on the dynamic impact of a debris flow on structures. In Proceedings of the International Symposium Interpraevent, Bern, Switzerland, 107$435 \quad 116$

437 Baecher GB, Christian JT (2003) Reliability and statistics in geotechnical engineering. Chichester. 438 West Sussex, England: Hoboken, NJ: J. Wiley

440 Callisto L (2010) A factored strength approach for the limit states design of geotechnical structures. 
Canadian Geotechnical Journal 47:1011-1023

442

443 Ditlevsen O (1981) Uncertainty modelling: with applications to multidimensional civil engineering 444 systems. New York: McGraw-Hill

Duncan JM (2000) Factors of safety and reliability in geotechnical engineering. Journal of 447 Geotechnical and Geoenvironmental Engineering 126(4):307-316

EN 1990 (2002) Eurocode - Basis of structural design. Brussels, Belgium, CEN

EN 1997-1 (2004) Eurocode 7: Geotechnical Design - Part 1: General rules. Brussels, Belgium, 452 CEN

Haldar A, Mahadevan S (1999) Probability, reliability and statistical methods in engineering design. 455 New York: J. Wiley

Harrison JP (2014) Eurocode 7 and rock engineering: current problems and future opportunities. In 458 Proceedings of EUROCK European Regional Symposium - Rock Engineering and Rock 459 Mechanics: Structures in and on Rock Masses, Vigo, Spain, 1531-1537.

461 Hasofer AM, Lind NC (1974) An exact and invariant second-moment code format. Journal of 462 Mechanical Division ASCE 100(1):111-121 
the fan of the Chalance torrent, Valgaudemar (French Alps). Earth Surface Processes and Landforms 27(12):1299-1307

Hong Y, Wang JP, Li DQ et al. (2015) Statistical and probabilistic analyses of impact pressure and discharge of debris flow from 139 events during 1961 and 2000 at Jiangjia Ravine, China.

Engineering Geology 187:122-134

Huang HW, Wen SC, Zhang J, et al. (2018) Reliability analysis of slope stability under seismic condition during a given exposure time. Landslides 15(11):2303-2313

Hungr O, Morgan GC, Kellerhals R (1984) Quantitative analysis of debris torrent hazard for design

Hubl J, Suda J, Proske D, et al. (2009) Debris flow impact estimation. In Proceedings of the $11^{\text {th }}$

Jakob M, Hungr O (2005) Debris-flow Hazards and Related Phenomena. Springer-Verlag Berlin

Heidelberg

Kang ZC, Cui P, Wei FQ, He SF (2006) Data collection of observation of debris flows in Jiangjia

Ravine, Dongchuan Debris Flow Observation and Research Station (1961-1984). Science Press,

Kang ZC, Cui P, Wei FQ, He SF (2007) Data collection of observation of debris flows in Jiangjia 
489 Ravine, Dongchuan Debris Flow Observation and Research Station (1995-2000). Science Press, 490 Beijing, China

492 Lamas L, Perucho A, Alejano LR (2014) Some key issues regarding application of Eurocode 7 to 493 rock engineering design. In Proceedings of EUROCK European Regional Symposium - Rock 494 Engineering and Rock Mechanics: Structures in and on Rock Masses, Vigo, Spain, 1459-1465.

495

496 Li DQ, Xiao T, Cao ZJ, Zhou CB, Zhang LM (2016) Enhancement of random finite element 497 method in reliability analysis and risk assessment of soil slopes using Subset Simulation. Landslides 498 13(2):293-303

500 Low BK, Tang Wilson H (1997) Efficient reliability evaluation using spreadsheet. Journal of 501 Engineering Mechanics, ASCE 749-752

Low BK, Tang Wilson H (2004) Reliability analysis using object-oriented constrained optimization. 504 Structural Safety, 26:69-89

505

506 Low BK, Tang Wilson H (2007) Efficient spreadsheet algorithm for first-order reliability method. 507 Journal of Engineering Mechanics, ASCE 133(12):1378-1387

509 Low BK, Phoon KK (2015) Reliability-based design and its complementary role to Eurocode 7 510 design approach. Computer and Geotechnics 65:30-44

512 Madsen HO, Krenk S, Lind NC (1986) Methods of structural safety. Englewood Cliffs. NJ: 
515 Marchi L, D’Agostino V (2004) Estimation of debris-flow magnitude in the eastern Italian Alps. 516 Earth Surface Processes and Landforms 29:207-220

518 McGuire MP, VandenBerge DR (2017) Interpretation of shear strength uncertainty and reliability 519 analyses of slopes. Landslides 14(6):2059-2072

521 Melchers RE (1999) Structural reliability analysis and prediction. $2^{\text {nd }}$ ed. New York: J. Wiley

Österreichischen Normungsinstituts Regeln (ONR, Austrian Standard Institute) 24800 (2009) 524 Protection works for torrent control - Terms and their definitions as well as classification. Wien, 525 Austria (in German)

Österreichischen Normungsinstituts Regeln (ONR, Austrian Standard Institute) 24802 (2011) 528 Protection works for torrent control - Design of structures. Wien, Austria (in German)

530 Rackwitz R, Fiessler B (1978) Structural reliability under combined random load sequences. 531 Computer\& Structures 9(5):484-494

533 Sun HW, Lam TTM, Tsui HM (2003) Design basis for standardised modules of landslide debris534 resisting barriers. GEO Report 174

536 Vagnon F, Segalini A, Ferrero AM (2015) Studies of Flexible Barriers under Debris Flow Impact: 
An Application to an Alpine Basin. In Proceedings of $1^{\text {st }}$ World Multidisciplinary Earth Sciences Symposium, 15: 165-172

Vagnon F and Segalini A (2016) Debris flow impact estimation on a rigid barrier. Natural Hazards Earth System Sciences, 16: 1691-1697, doi:10.5194/nhess-16-1691-2016.

Vagnon F, Ferrero AM, Segalini A (2016) EC7 design approach for debris flow flexible barriers: applicability and limitations. In Proceedings of EUROCK 2016 ISRM International Symposium Rock Mechanics and Rock Engineering: from the past to the future. Cappadocia, Turkey, 28-31 August 2016

Vagnon F, Ferrero AM, Segalini A, Pirulli M (2016) Experimental study for the design of flexible barriers under debris flow impact. In Landslides and Engineered Slopes. Experience, Theory and Practice 1951-1956

Vagnon F, Ferrero AM, Umili G, Segalini A (2017) A factor strength approach for the design of rock fall and debris flow barriers. Geotechnical and Geological Engineering 1-13

Vagnon F, Bonetto SMR, Ferrero AM, Migliazza MR, Umili G (2020) Rock-engineering design and NTC 2018: some open questions. In Geotechnical Research for Land Protection and Development 519-528 DOI: 10.1007/978-3-030-21359-6_55

Zhang J, Xiong G (1997) Data collection of kinematic observation of debris flows in Jiangjia Ravine, Dongchuan, Yunnan (1987-1994). Science Press, Beijing, China 
562 Zhao L, Zuo S, Lin Y, Li L, Zhang Y (2016) Reliability back analysis of shear strength parameters 563 of landslide with three-dimensional upper bound limit analysis theory. Landslides 13:711-724 564

565 Zhou GGD, Ng CWW (2010) Dimensional analysis of natural debris flows. Canadian Geotechnical 566 Journal 47(7):719-729 
568 Table 1. Principal laboratory and field dataset features.

\begin{tabular}{|c|c|c|c|c|c|c|}
\hline & Dataset & Apparatus/Basin & Material & $\begin{array}{c}\text { Measured } \\
\text { Physical } \\
\text { Quantities } \\
\end{array}$ & $\begin{array}{c}\text { Dimension } \\
\text { of the } \\
\text { dataset } \\
\end{array}$ & $\begin{array}{c}\text { Range of } \\
\text { variation of } \\
\text { parameters }\end{array}$ \\
\hline $\begin{array}{l}\text { Laboratory } \\
\text { experiments }\end{array}$ & $\begin{array}{l}\text { Vagnon } \\
\text { and } \\
\text { Segalini, } \\
2016\end{array}$ & $\begin{array}{l}\text { Steel flume } 4 \mathrm{~m} \\
\text { long and } 0.39 \mathrm{~m} \\
\text { wide in which the } \\
\text { slope varies } \\
\text { between } 30^{\circ} \text { and } \\
35^{\circ}\end{array}$ & $\begin{array}{c}\text { Saturated } \\
\text { sand with } \\
\text { constant } \\
\text { liquid } \\
\text { concentration } \\
(0.4) \text { and } \\
\text { mixture } \\
\text { density ( } 1920 \\
\left.\mathrm{kgm}^{-3}\right) \text {. Grain } \\
\text { size } \\
\text { distribution } \\
\text { varies } \\
\text { between } \\
0.0001 \text { and } 5 \\
\text { mm }\end{array}$ & $\begin{array}{l}\text { Flow } \\
\text { velocity, } \\
\text { impact } \\
\text { height and } \\
\text { impact } \\
\text { forces } \\
\text { recorded } \\
\text { in real } \\
\text { time } \\
\text { during the } \\
\text { experiment } \\
\text { s }\end{array}$ & $\begin{array}{l}82 \text { tests with } \\
\text { different } \\
\text { volumes and } \\
\text { different } \\
\text { slopes }\end{array}$ & $\begin{array}{c}\mathrm{v}_{\mathrm{f}}: 1.16-6.74 \mathrm{~ms}^{-1} \\
\mathrm{~h}_{\mathrm{f}}: 0.01-0.07 \mathrm{~m} \\
\alpha: 0.44-3.44\end{array}$ \\
\hline $\begin{array}{c}\text { Field } \\
\text { measurements }\end{array}$ & $\begin{array}{l}\text { Hong et } \\
\text { al., } 2015\end{array}$ & $\begin{array}{c}\text { Jiangjia Ravine } \\
\text { basin (near } \\
\text { Dongchuan city, } \\
\text { China). Area } 48.6 \\
\mathrm{~km}^{2} \text { and } \\
\text { mainstream length } \\
13.9 \mathrm{~km}\end{array}$ & $\begin{array}{c}\text { Bulk density } \\
\text { ranges from } \\
1600 \text { to } 2300 \\
\mathrm{kgm}^{-3} \text { with } \\
\text { fluid } \\
\text { concentration } \\
\text { ranging from } \\
0.15 \text { to } 0.6 . \\
\text { Solid particle } \\
\text { dimensions } \\
\text { vary between } \\
0.001 \text { and } 100 \\
\mathrm{~mm}\end{array}$ & $\begin{array}{c}\text { Channel } \\
\text { width, } \\
\text { flow } \\
\text { velocity, } \\
\text { impact } \\
\text { height, } \\
\text { density, } \\
\text { duration } \\
\text { and impact } \\
\text { forces } \\
\text { recorded } \\
\text { in real } \\
\text { time } \\
\text { during } \\
\text { debris } \\
\text { flow } \\
\text { events }\end{array}$ & $\begin{array}{l}139 \text { events } \\
\text { from } 1961 \\
\text { to } 2000\end{array}$ & $\begin{array}{c}\mathrm{v}_{\mathrm{f}}: 3-20 \mathrm{~ms}^{-1} \\
\mathrm{~h}_{\mathrm{f}}: 0.1-6.4 \mathrm{~m} \\
\alpha: 0.06-8\end{array}$ \\
\hline
\end{tabular}


570 Table 2. Main statistical parameters for the laboratory and field datasets.

\begin{tabular}{|c|c|c|c|c|c|c|}
\hline \multirow[t]{2}{*}{ Parameter } & \multicolumn{3}{|c|}{$\begin{array}{c}\text { Laboratory data } \\
\text { Value }\end{array}$} & \multicolumn{3}{|c|}{$\begin{array}{l}\text { Field data } \\
\text { Value }\end{array}$} \\
\hline & $\mathrm{v}_{\mathrm{f}}[\mathrm{m} / \mathrm{s}]$ & $\mathrm{h}_{\mathrm{f}}[\mathrm{m}]$ & $\alpha[-]$ & $\mathrm{v}_{\mathrm{f}}[\mathrm{m} / \mathrm{s}]$ & $\mathrm{h}_{\mathrm{f}}[\mathrm{m}]$ & $\alpha[-]$ \\
\hline $\operatorname{Mean}(\mu)$ & 3.67 & 0.05 & 1.21 & 10 & 1.6 & 1.36 \\
\hline Variance $\left(\sigma^{2}\right)$ & 1.28 & 0.0003 & 0.27 & 10 & 1.2 & 1.53 \\
\hline Standard deviation $(\sigma)$ & 1.13 & 0.02 & 0.52 & 3 & 1.1 & 1.24 \\
\hline Coefficient of variation $(\mathrm{CV})$ & 0.31 & 0.35 & 0.43 & 0.33 & 0.69 & 0.91 \\
\hline Asimmetry coefficient $(\gamma)$ & 0.69 & -0.45 & 1.62 & 0.22 & 1.12 & 2.71 \\
\hline Maximum & 6.74 & 0.07 & 3.44 & 20 & 6.4 & 8.01 \\
\hline Minimum & 1.16 & 0.01 & 0.44 & 3 & 0.1 & 0.06 \\
\hline Coefficient of correlation v-h & \multicolumn{3}{|c|}{-0.6} & \multicolumn{3}{|c|}{-0.6} \\
\hline Coefficient of correlation $v-\alpha$ & \multicolumn{3}{|c|}{-0.5} & \multicolumn{3}{|c|}{-0.5} \\
\hline Coefficient of correlation $h-\alpha$ & \multicolumn{3}{|c|}{-} & \multicolumn{3}{|c|}{-} \\
\hline Number of experimental tests & \multicolumn{3}{|c|}{82} & \multicolumn{3}{|c|}{139} \\
\hline $\begin{array}{l}\text { Number of classes (defined using } \\
\text { Equation } 3 \text { ) }\end{array}$ & \multicolumn{3}{|c|}{12} & \multicolumn{3}{|c|}{14} \\
\hline
\end{tabular}


572 Table 3. Laboratory measurements: two statistical goodness-of-fit test results for $\mathrm{v}_{\mathrm{f}}, \mathrm{h}_{\mathrm{f}}$ and $\alpha$.

\begin{tabular}{|c|c|c|c|c|c|c|c|c|c|}
\hline \multirow[t]{2}{*}{ Variable } & \multirow[t]{2}{*}{ Results } & & \multicolumn{7}{|c|}{ Probabilistic model } \\
\hline & & & Normal & Lognormal & Exponential & Gumbel & GEV & Gamma & Weibull \\
\hline \multirow{6}{*}{$\mathbf{v}_{\mathbf{f}}$} & $\begin{array}{l}\text { Chi-square } \\
\text { test }\end{array}$ & $\chi^{2}$ & 17.51 & 80.44 & 153.32 & 9.90 & 15.34 & 20.63 & 19.95 \\
\hline & $\begin{array}{l}\text { Critical } \\
\text { value }\end{array}$ & $\chi^{2} \lim$ & 16.92 & 16.92 & 18.31 & 16.92 & 15.51 & 16.92 & 16.92 \\
\hline & Suitability & & NO & NO & NO & YES & YES & NO & NO \\
\hline & $\mathrm{AD}$ test & $\mathrm{A}^{2}$ & & & & 0.196 & 0.458 & & \\
\hline & $\begin{array}{l}\text { Critical } \\
\text { value }\end{array}$ & $\mathrm{A}^{2}{ }_{\lim }$ & & & & 0.461 & 0.461 & & \\
\hline & Suitability & & & & & YES & YES & & \\
\hline \multirow{6}{*}{$\mathbf{h}_{\mathbf{f}}$} & $\begin{array}{l}\text { Chi-square } \\
\text { test }\end{array}$ & $\chi^{2}$ & 19.27 & 399.46 & 126.39 & 28.05 & 8.44 & 18.98 & 13.80 \\
\hline & $\begin{array}{l}\text { Critical } \\
\text { value }\end{array}$ & $\chi_{\lim }^{2}$ & 16.92 & 16.92 & 18.31 & 16.92 & 15.51 & 16.92 & 16.92 \\
\hline & Suitability & & $\mathrm{NO}$ & $\mathrm{NO}$ & $\mathrm{NO}$ & $\mathrm{NO}$ & YES & NO & YES \\
\hline & $\mathrm{AD}$ test & $\mathrm{A}^{2}$ & & & & & 0.279 & & 0.917 \\
\hline & $\begin{array}{l}\text { Critical } \\
\text { value }\end{array}$ & $\mathrm{A}^{2} \lim$ & & & & & 0.461 & & 0.461 \\
\hline & Suitability & & & & & & YES & & NO \\
\hline \multirow{6}{*}{$\alpha$} & $\begin{array}{l}\text { Chi-square } \\
\text { test }\end{array}$ & $\chi^{2}$ & 16.34 & 146.29 & 97.41 & 14.88 & 13.41 & 22.59 & 64.93 \\
\hline & $\begin{array}{l}\text { Critical } \\
\text { value }\end{array}$ & $\chi_{\lim }^{2}$ & 16.92 & 16.92 & 18.31 & 16.92 & 15.51 & 16.92 & 16.92 \\
\hline & Suitability & & YES & NO & NO & YES & YES & NO & NO \\
\hline & $\mathrm{AD}$ test & $\mathrm{A}^{2}$ & 2.65 & & & 0.283 & 0.440 & & \\
\hline & $\begin{array}{l}\text { Critical } \\
\text { value }\end{array}$ & $\mathrm{A}^{2} \mathrm{lim}$ & 0.46 & & & 0.461 & 0.461 & & \\
\hline & Suitability & & $\mathrm{NO}$ & & & YES & YES & & \\
\hline
\end{tabular}


574 Table 4. Field measurements: two statistical goodness-of-fit test results for $\mathrm{v}_{\mathrm{f}}$ and $\mathrm{h}_{\mathrm{f}}$.

\begin{tabular}{|c|c|c|c|c|c|c|c|c|c|}
\hline \multirow[t]{2}{*}{ Variable } & \multirow[t]{2}{*}{ Results } & & \multicolumn{7}{|c|}{ Probabilistic model } \\
\hline & & & Normal & Lognormal & Exponential & Gumbel & GEV & Gamma & Weibull \\
\hline \multirow{6}{*}{$\mathbf{v}_{\mathbf{f}}$} & $\begin{array}{l}\text { Chi-square } \\
\text { test }\end{array}$ & $\chi^{2}$ & 25.64 & 42.44 & 196.54 & 29.37 & 22.73 & 24.81 & 26.05 \\
\hline & $\begin{array}{l}\text { Critical } \\
\text { value }\end{array}$ & $\chi^{2} \lim$ & 24.72 & 24.72 & 26.22 & 24.72 & 23.21 & 24.72 & 24.72 \\
\hline & Suitability & & NO & NO & NO & NO & YES & NO & NO \\
\hline & $\mathrm{AD}$ test & $A^{2}$ & & & & & 0.93 & & \\
\hline & $\begin{array}{l}\text { Critical } \\
\text { value }\end{array}$ & $\mathrm{A}^{2}{ }_{\lim }$ & & & & & 0.461 & & \\
\hline & Suitability & & & & & & NO & & \\
\hline \multirow{6}{*}{$\mathbf{h}_{\mathbf{f}}$} & $\begin{array}{l}\text { Chi-square } \\
\text { test }\end{array}$ & $\chi^{2}$ & 26.88 & 39.53 & 33.93 & 8.21 & 8.21 & 12.78 & 8.63 \\
\hline & $\begin{array}{l}\text { Critical } \\
\text { value }\end{array}$ & $\chi^{2} \lim$ & 19.68 & 19.68 & 21.03 & 19.68 & 18.31 & 18.68 & 19.68 \\
\hline & Suitability & & NO & NO & NO & YES & YES & YES & YES \\
\hline & $\mathrm{AD}$ test & $\mathrm{A}^{2}$ & & & & 0.230 & 0.447 & 0.471 & 0.119 \\
\hline & $\begin{array}{l}\text { Critical } \\
\text { value }\end{array}$ & $\mathrm{A}^{2} \lim$ & & & & 0.461 & 0.461 & 0.461 & 0.461 \\
\hline & Suitability & & & & & YES & YES & NO & YES \\
\hline \multirow{6}{*}{$\boldsymbol{\alpha}$} & $\begin{array}{l}\text { Chi-square } \\
\text { test }\end{array}$ & $\chi^{2}$ & 96.99 & 18.79 & 59.47 & 67.33 & 12.99 & 45.13 & 44.30 \\
\hline & $\begin{array}{l}\text { Critical } \\
\text { value }\end{array}$ & $\chi^{2} \lim$ & 19.68 & 19.68 & 21.03 & 19.68 & 18.31 & 18.68 & 19.68 \\
\hline & Suitability & & NO & YES & NO & $\mathrm{NO}$ & YES & NO & NO \\
\hline & $\mathrm{AD}$ test & $\mathrm{A}^{2}$ & & -13.91 & & & -7.67 & & \\
\hline & $\begin{array}{l}\text { Critical } \\
\text { value }\end{array}$ & $\mathrm{A}^{2} \lim$ & & 0.461 & & & 0.461 & & \\
\hline & Suitability & & & YES & & & YES & & \\
\hline
\end{tabular}


576 Table 5. Relationship between $\mathrm{P}_{\mathrm{f}}$ and $\beta$.

\begin{tabular}{cccccccc}
\hline $\mathrm{P}_{\mathrm{f}}$ & $1.00 \mathrm{E}-01$ & $1.00 \mathrm{E}-02$ & $1.00 \mathrm{E}-03$ & $1.00 \mathrm{E}-04$ & $1.00 \mathrm{E}-05$ & $1.00 \mathrm{E}-06$ & $1.00 \mathrm{E}-07$ \\
$\beta$ & 1.28 & 2.32 & 3.09 & 3.72 & 4.27 & 4.75 & 5.2 \\
\hline
\end{tabular}

577 
578 Table 6. Design parameters evaluated after RBD approach as a function of reliability index values 579 suggested by Annex C of EN 1990.

\begin{tabular}{cccccccccc}
\hline \multirow{2}{*}[-]{} & \multirow{2}{*}{$\mathbf{P}_{\mathbf{f}}[-]$} & \multicolumn{4}{c}{ Laboratory data } & \multicolumn{5}{c}{ Field data } \\
\cline { 3 - 9 } & & $\mathbf{R}^{*}[\mathbf{N}]$ & $\mathbf{v}_{\mathbf{f}}^{*}[\mathbf{m} / \mathbf{s}]$ & $\boldsymbol{\alpha}^{*}[-]$ & $\mathbf{h}_{\mathbf{f}}{ }^{*}[\mathbf{m}]$ & $\mathbf{R}^{*}[\mathbf{N}]$ & $\mathbf{v}_{\mathbf{f}}^{*}[\mathbf{m} / \mathbf{s}]$ & $\boldsymbol{\alpha}^{*}[-]$ & $\mathbf{h}_{\mathbf{f}}{ }^{*}[\mathbf{m}]$ \\
\hline 1.28 & $1 \mathrm{E}-01$ & 811.98 & 4.12 & 1.27 & 0.05 & $5.70 \mathrm{E}+07$ & 12.17 & 2.22 & 2.24 \\
2.32 & $1 \mathrm{E}-02$ & 1219.21 & 4.72 & 1.46 & 0.05 & $1.60 \mathrm{E}+08$ & 14.19 & 3.29 & 3.12 \\
3.09 & $1 \mathrm{E}-03$ & 1639.49 & 5.22 & 1.61 & 0.05 & $3.18 \mathrm{E}+08$ & 15.57 & 4.28 & 3.96 \\
3.72 & $1 \mathrm{E}-04$ & 2089.45 & 5.31 & 1.98 & 0.05 & $5.35 \mathrm{E}+08$ & 16.57 & 5.24 & 4.79 \\
4.27 & $1 \mathrm{E}-05$ & 2589.75 & 5.45 & 2.39 & 0.05 & $8.15 \mathrm{E}+08$ & 17.35 & 6.20 & 5.63 \\
4.75 & $1 \mathrm{E}-06$ & 3129.86 & 5.52 & 2.77 & 0.05 & $1.16 \mathrm{E}+09$ & 17.96 & 7.15 & 6.45 \\
5.2 & $1 \mathrm{E}-07$ & 3719.91 & 5.57 & 3.23 & 0.05 & $1.57 \mathrm{E}+09$ & 18.47 & 8.12 & 7.30 \\
\hline
\end{tabular}




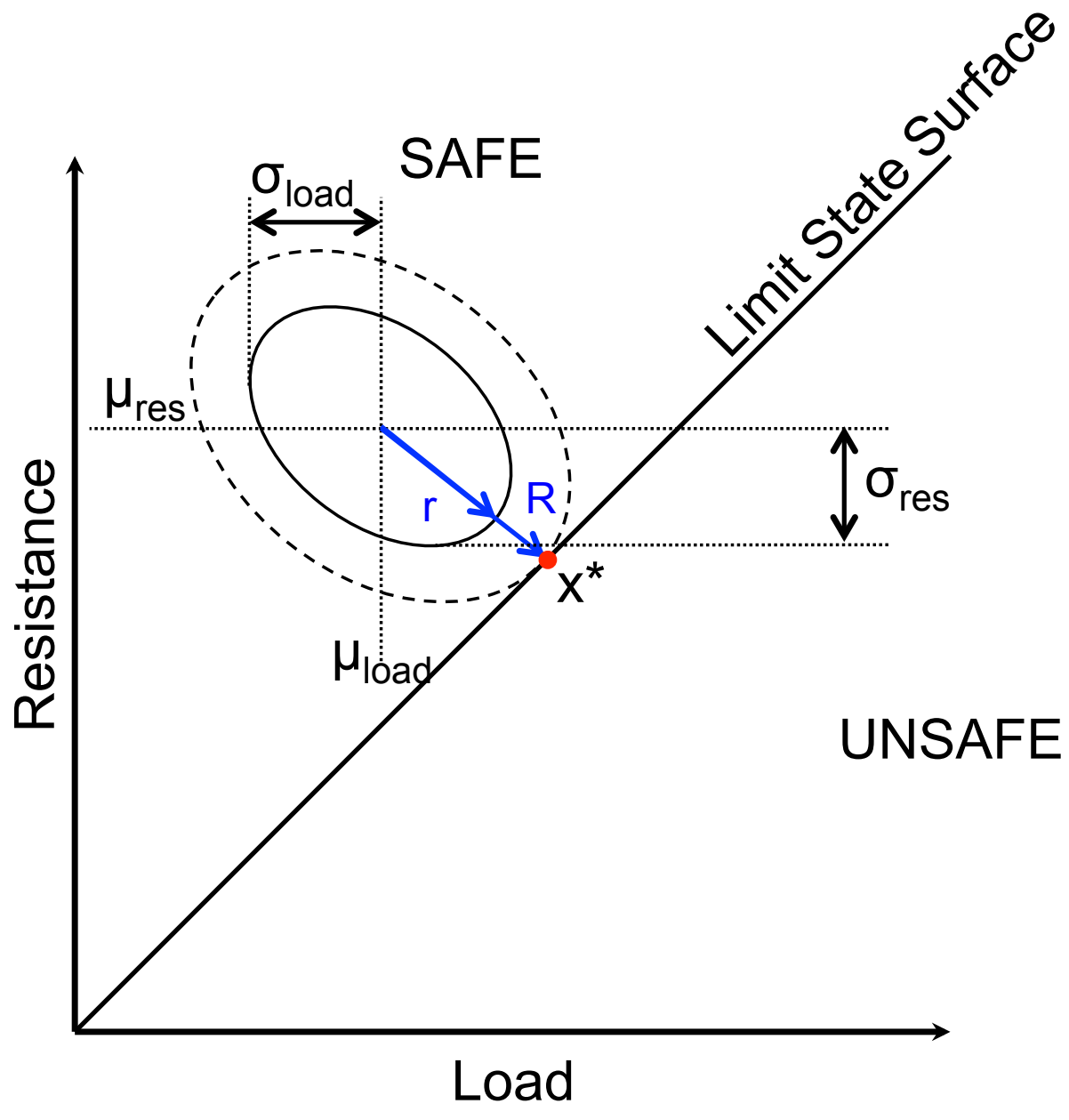

583 Figure 1. Illustration of the reliability index in a plane with two negatively correlated random 584 variables. 


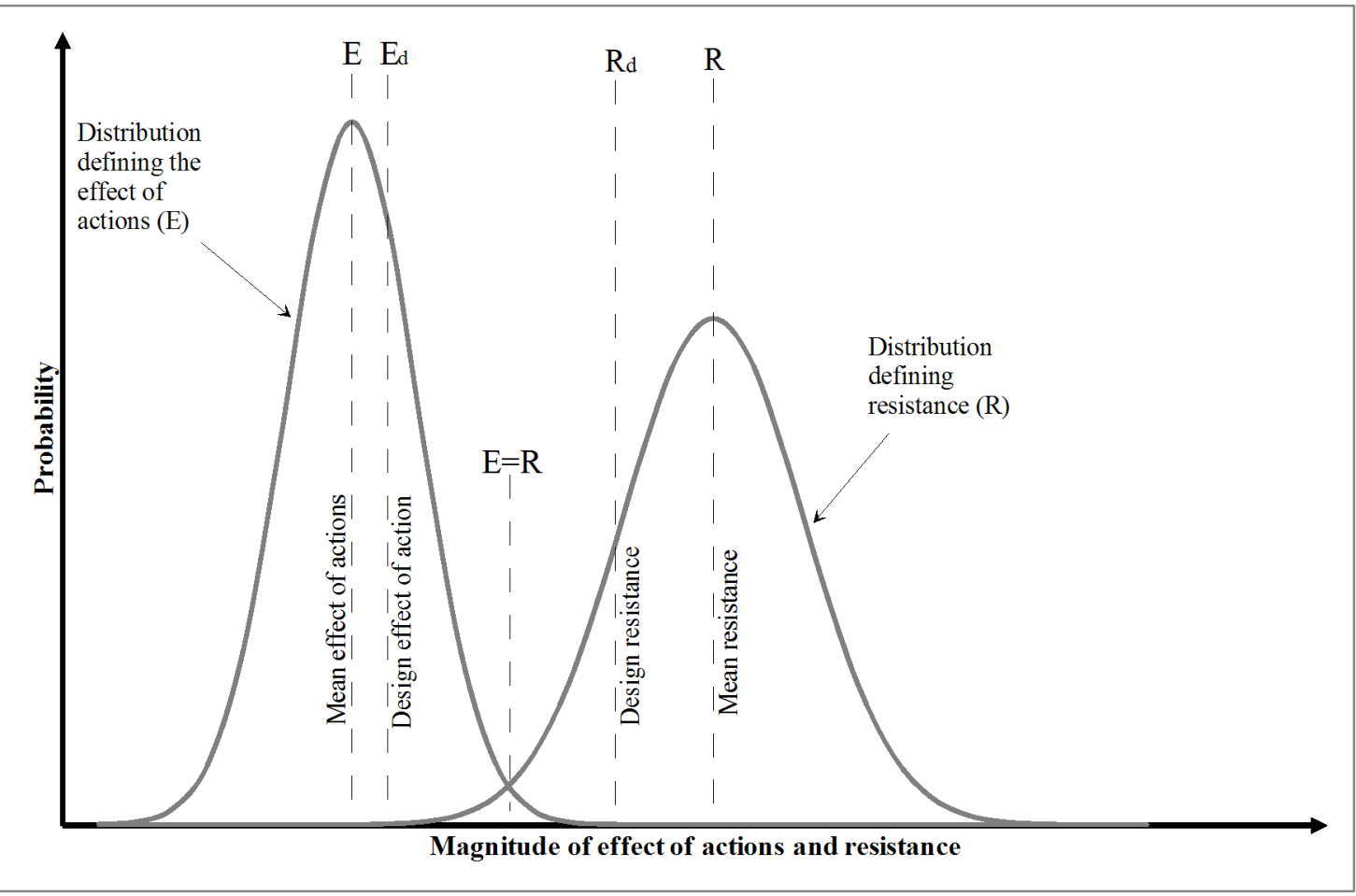

586 Figure 2. EC7 limit state design: probabilities of actions and material resistance. 


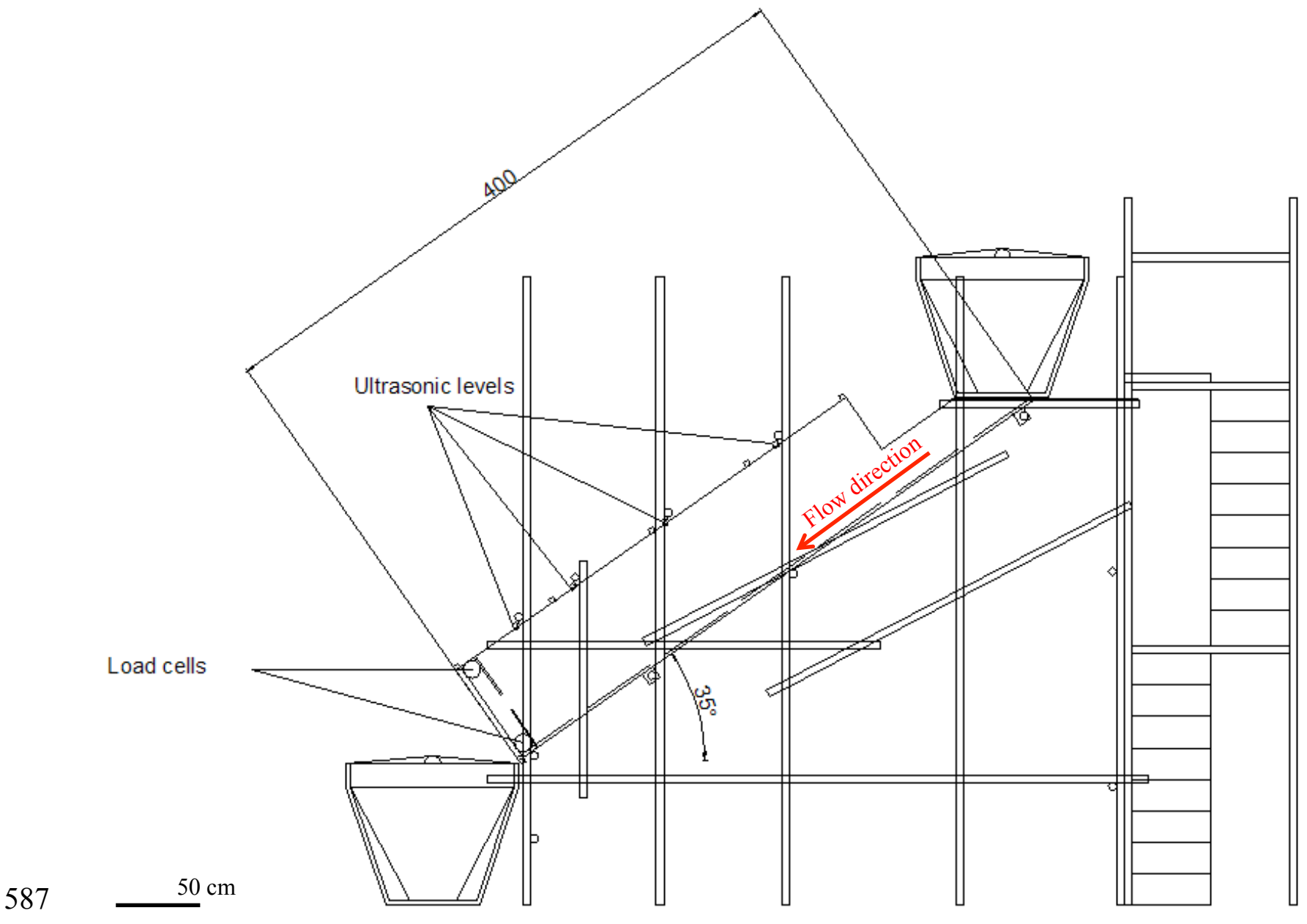

588 Figure 3. Flume setup and location of measurement devices. 

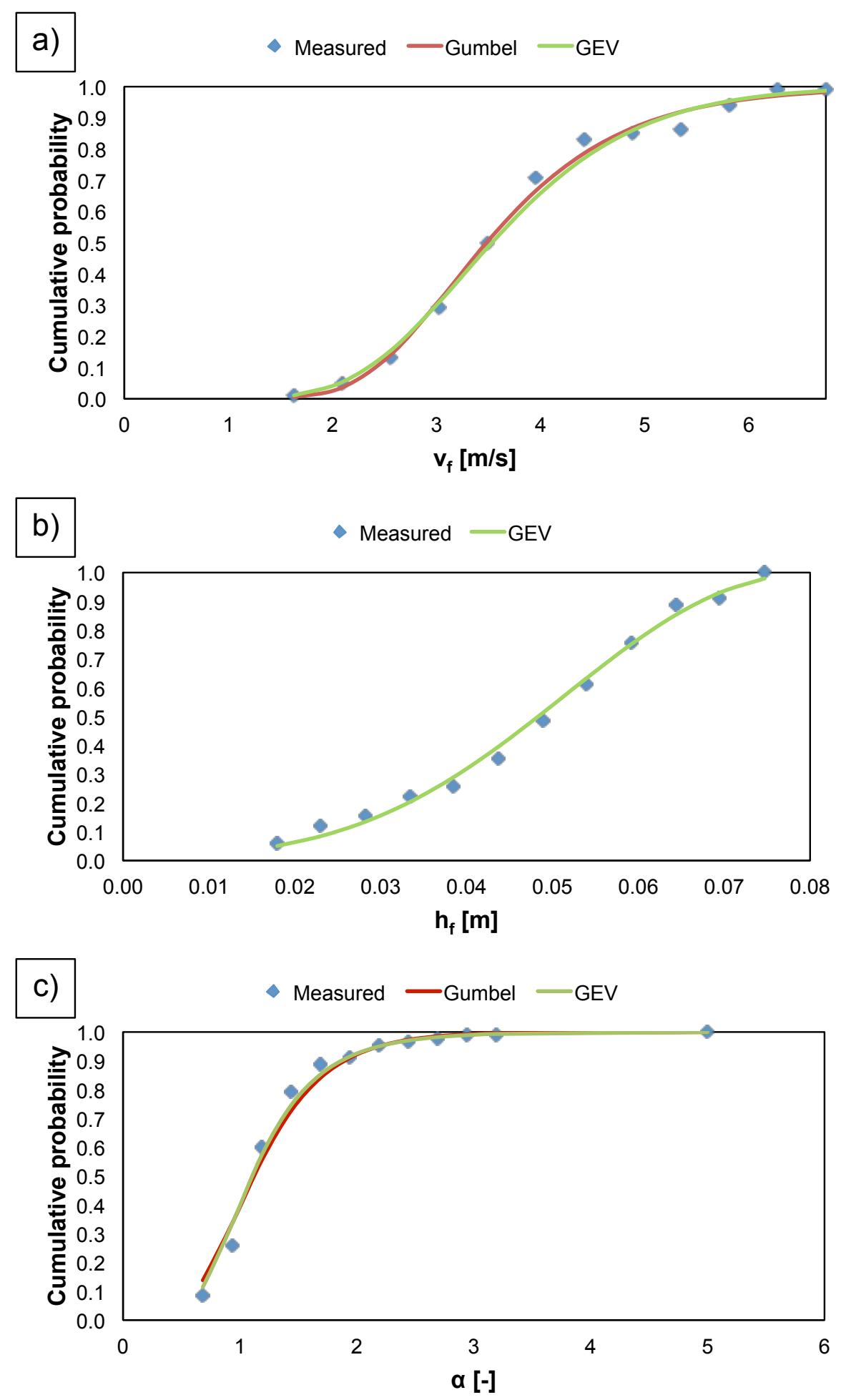

590 Figure 4. Laboratory data: comparison of cumulative probability distributions for measured and 591 theoretically predicted $\mathrm{v}_{\mathrm{f}}(\mathrm{a}), \mathrm{h}_{\mathrm{f}}(\mathrm{b})$, and $\alpha(\mathrm{c})$. 

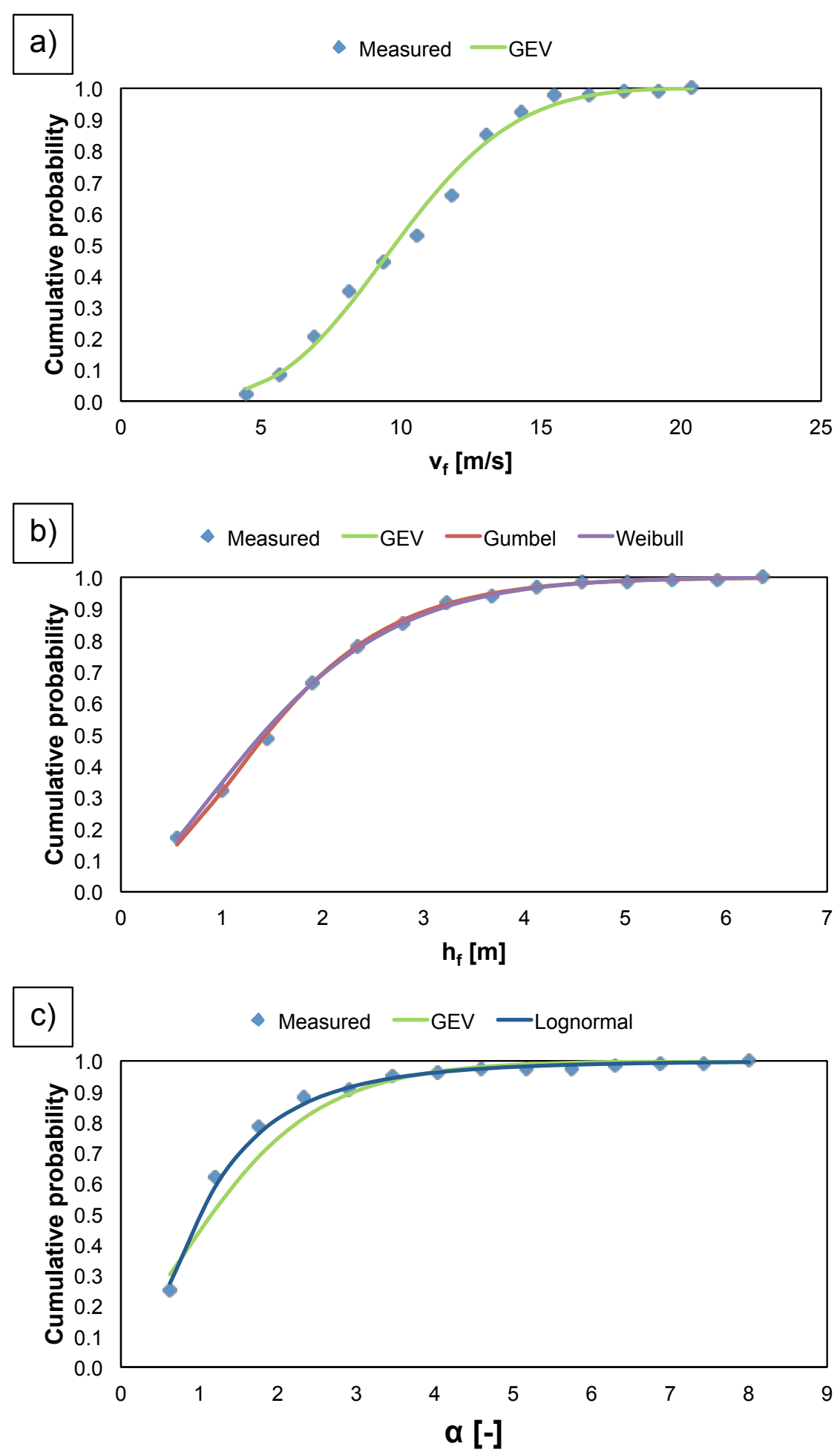

593 Figure 5. Field data: comparison of the cumulative probability distributions for measured and 594 theoretically predicted $\mathrm{v}_{\mathrm{f}}(\mathrm{a}), \mathrm{h}_{\mathrm{f}}(\mathrm{b})$ and $\alpha(\mathrm{c})$. 


\begin{tabular}{|c|c|c|c|c|}
\hline $\begin{array}{c}\text { Distribution } \\
\text { Normal } \\
\text { GEV } \\
\text { GEV } \\
\text { GEV }\end{array}$ & $\begin{array}{c}\text { R } \\
\text { vf } \\
\text { alfa } \\
\text { hf }\end{array}$ & $\begin{array}{c}\text { Para1 } \\
1570000000 \\
10 \\
1.36 \\
1.6\end{array}$ & $\begin{array}{c}\text { Para2 } \\
4.71 \mathrm{E}+07 \\
3 \\
1.24 \\
1.1\end{array}$ & \\
\hline \multicolumn{4}{|c|}{ Correlation matrix [R] } & $\mathbf{n}$ \\
\hline 1 & 0 & 0 & 0 & $-2 \mathrm{E}-14$ \\
\hline 0 & 1 & -0.5 & -0.6 & $3 \mathrm{E}+00$ \\
\hline 0 & -0.5 & 1 & 0 & $3 E+00$ \\
\hline 0 & -0.6 & 0 & 1 & $3 \mathrm{E}+00$ \\
\hline
\end{tabular}

$\begin{array}{ccc}\mathbf{X}^{*} & \boldsymbol{\mu}^{\mathrm{N}} & \boldsymbol{\sigma}^{\mathrm{N}} \\ 1.57 \mathrm{E}+09 & 1.57 \mathrm{E}+09 & 4.71 \mathrm{E}+07 \\ 18.47 & 10.87 & 3.01 \\ 8.12 & -3.12 & 3.43 \\ 7.30 & -2.03 & 2.97\end{array}$

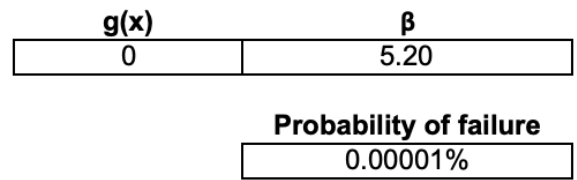

595

596 Figure 6. Determining the reliability index $\beta$ and the coordinates of the design point $x^{*}$ for a 597 hypothetical rigid debris flow barrier. 

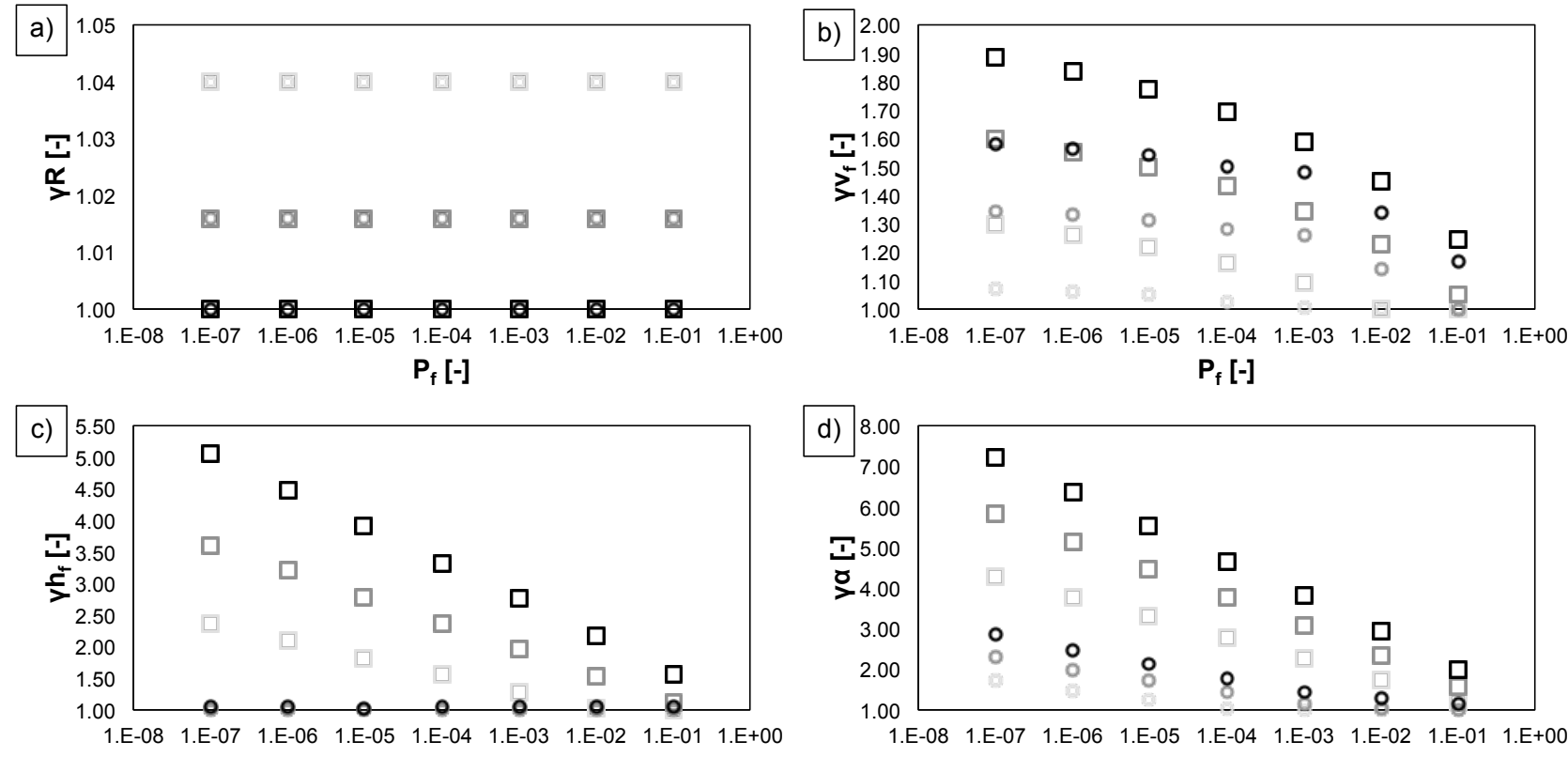

$P_{\mathrm{f}}[-]$

$P_{f}[-]$

Laboratory data -90 th percentile

- Laboratory data -70 th percentile

O Laboratory data -50 th percentile

Field data -90 th percentile

$\square$ Field data -70 th percentile

$\square$ Field data -50 th percentile

599 Figure 7. Partial safety factor dependence on resistance (a), velocity (b), thickness (c) and dynamic

600 coefficient (d) as a function of probability of failure for laboratory data (circles) and field data

601 (squares). Three percentiles were considered for each parameter probability distribution: $50^{\text {th }}$ 602 (black), $70^{\text {th }}$ (dark grey) and $90^{\text {th }}$ (light grey). 